\title{
Morphology, Chemical Characterization and Sources of Microplastics in a Coastal City in The Equatorial Zone With Diverse Anthropogenic Activities (Fortaleza City, Brazil)
}

\section{Maria E. N. Banegas}

Federal University of Ceara Marine Science Institute Labomar: Universidade Federal do Ceara Instituto de Ciencias do Mar Labomar

Viviane A. S. Lemos

Federal University of Ceara Marine Science Institute Labomar: Universidade Federal do Ceara Instituto de Ciencias do Mar Labomar

Gina L. L. Flores

Federal University of Ceara Marine Science Institute Labomar: Universidade Federal do Ceara Instituto de Ciencias do Mar Labomar

\section{Sandra A. Soares}

UFC: Universidade Federal do Ceara

\section{Johnny Feitosa}

UFC: Universidade Federal do Ceara

\section{Bruno S. Araújo}

UFC: Universidade Federal do Ceara

\section{Alejandro P. Ayala}

UFC: Universidade Federal do Ceara

\section{Marleane M. F. de Azevedo}

UFPI: Universidade Federal do Piaui

\section{Francisco E. P. Santos}

UFPI: Universidade Federal do Piaui

Rivelino Martins Cavalcante ( $\square$ rivelino@ufc.br)

Universidade Federal do Ceará https://orcid.org/0000-0003-1241-4529

\section{Research Article}

Keywords: Microplastics, Marine environments, Morphological characterization, Chemical characterization

Posted Date: December 16th, 2021 
DOI: https://doi.org/10.21203/rs.3.rs-1166452/v1

License: (c) (1) This work is licensed under a Creative Commons Attribution 4.0 International License. Read Full License 


\section{Abstract}

The aim of the present study was to perform morphological and chemical characterizations of microplastics (MPs) found in seawater samples from the coast of the city of Fortaleza (CE) using Fouriertransform infrared (FTIR) spectroscopy, Raman spectroscopy and differential scanning calorimetry (DSC). Sampling was performed using a neuston sampler. MPs were separated based on the difference in density. MPs with varied morphologies were found. Fibers and fragments were the most abundant ( $57 \%$ and $36.2 \%$, respectively). FTIR, Raman spectroscopy and DSC confirmed the presence of polyurethane and alkyd resin, polyethylene, polypropylene, polystyrene, polyamide blends, thermoplastic rubber and polyester fibers. Many studies have chemically characterized plastic materials using FTIR, Raman spectroscopy and DSC and common MPs, such as polyethylene, polypropylene, polyamide and polyester, have been characterized. However, characterization becomes more complex when MPs are less common particles, weathered particles and blends of polymers and additives. There is also less information on these types of MPs in commercial polymer databases. Therefore, the MP spectra obtained in this study can serve as a database to compare and characterize common as well as less common, more complex MPs.

\section{Introduction}

The world production of virgin plastic has increased 200 times since 1950 [1] due to its low cost and versatility compared to other materials, such as glass or metal [2]. In 2018, plastic production reached approximately 360 million metric tons (t) [3], at least $75 \%$ of which has already turned into garbage [4]. According to the World Bank, Brazil became the 4th largest producer of plastic waste in the world in 2018, with 11.3 million tons generated per year, only $1.28 \%$ of which is properly recycled $[2,4]$.

Plastic pollution is currently one of the largest concerns and threats to the environment and is considered an emerging contaminant by the National Oceanographic and Atmospheric Administration (NOAA) due to the multiple risks posed to the environment [5]. Plastic pollution also contributes $6 \%$ of annual carbon dioxide $\left(\mathrm{CO}_{2}\right)$ emissions in the world due to the high production and incineration of plastic waste, which favors climate change. Poor waste management and the continuous increase in human activities are the main causes of the indiscriminate discarding of plastics in the environment [2]. Due to factors such as weathering, ultraviolet radiation, mechanical forces and microbes, discarded plastic is broken down into microplastics (MPs) [6]. The degradation of plastic involves the breakage primary bonds of the polymer main chain [7]. The material is weakened over time, becoming brittle enough to break into fragments [8].

The term microplastic was coined by Thompson et al. in 2004. MPs were subsequently defined as particles of synthetic polymers from $1 \mu \mathrm{m}$ to $5 \mathrm{~mm}$ in size [10] with different chemical compositions and structures (posing an analytical challenge) and are classified as primary or secondary, depending on the source of origin [11]. Primary MPs are those produced for industrial and domestic purposes [12,13] and secondary MPs are products of the degradation of larger plastics [14]. MPs are currently present in the main marine environments, such as the water column and sediments on the bottom of seas $[13,15]$. 
MPs are considered a source of chemical contamination due to their ability to absorb and transport chemical pollutants [16] and the fact that they contain chemical additives that can be desorbed and are harmful to marine life $[15,16]$. Many marine species confuse MPs with food $[17,18]$. The transfer of harmful pollutants to marine organisms occurs through the ingestion, inhalation and dermal absorption of MPs [16], the negative effects of which include a reduction in energy available for reproductive processes and growth [19], decreased immunity and mobility, malformations [20,21], disturbances of the endocrine system [16], inflammation, liver stress, blockage of the digestive tract and intestinal damage, which can lead to the death of organisms $[13,17]$. Moreover, absorption by plastics inhibits the biodegradation of chemical pollutants and contributes to their persistence in the environment [16]. Thus, considerable interest has been generated among researchers around the world to find solutions that enable the cessation of plastic pollution [11].

The study of microplastic pollution in aquatic ecosystems has increased in the last decade. However, further investigation is needed on the morphological and chemical characterization of MPs, possible sources, trends and abundances as well as effects on organisms, trophic transference and the standardization of methods to enable comparisons across studies [22]. Therefore, the aim of the present investigation was to perform morphological and chemical characterizations of MPs in seawater samples collected on the coast of the city of Fortaleza, Brazil, to provide information on possible sources of MPs in the marine environment and assist in establishing measures to avoid contamination by MPs. The results reported herein could be useful for studies addressing coastal regions with multiple human activities and may help sensitize public administrators to invest in an agenda of sustainable urban growth.

\section{Materials And Methods \\ 2.1 Study area}

The study area was the coast of the city of Fortaleza, which is the capital of the state of Ceará, Brazil (Fig. 1). The city is located on the Atlantic coast in the northeastern region of the country and is characterized by a tropical climate. The rainy season extends from February to July and the dry season is from August to December [23]. The city is densely populated and home to port activities (Mucuripe Port) as well as fishing, tourism and industrial activities [24]. The metropolitan region of Fortaleza is one of the most developed in Brazil and, according to the Brazilian Institute of Geography and Statistics (IBGE), had an estimated population of 2,686.612 residents in 2020 [25].

\subsection{Sampling}

Seawater samples were collected along five transects (Fig. 1.) aboard the research vessel "Argo Equatorial" using a neuston sampler at a speed of $5 \mathrm{~km} \mathrm{~h}^{-1}$ and coupled to a flowmeter. The sampler had a rectangular stainless-steel mouth $(60 \times 24 \mathrm{~cm})$, a two-meter-wide white polyamide net and a $100-\mu \mathrm{m}$ 
mesh collector and was strapped to the side of the boat using a support. Five samples were collected, with a total volume of $8251.26 \mathrm{~m}^{3}$ of surface water filtered.

\subsection{Analysis of samples}

The analysis method was adapted from Masura et al. (2015), as many plastics float in concentrated saline solutions. For extraction, each sample was placed in the oven at $90^{\circ} \mathrm{C}$ until the complete evaporation of water. Next, $20 \mathrm{~mL}$ of $35 \%$ hydrogen peroxide $\left(\mathrm{H}_{2} \mathrm{O}_{2}\right)$ were added for the digestion of organic matter, with the repetition of the procedure until complete digestion. Six grams of sodium chloride $(\mathrm{NaCl})$ were then added to increase the concentration of the aqueous solution by approximately $5 \mathrm{~mol}$ $\mathrm{L}^{-1}$. The contents were transferred to a simple glass funnel to allow the MP particles to float. The supernatant was filtered through $65-\mu \mathrm{m}$ polyamide mesh and left to dry at room temperature. The filtrate was then submitted to visual analysis. MPs were isolated, counted, photographed and morphologically characterized using a stereoscopic microscope. The particles were grouped into 14 clean Eppendorf tubes for subsequent chemical characterization.

Chemical characterization was performed using FTIR spectroscopy, Raman spectroscopy and DSC [11, $18,27,28]$. For the FTIR analyses, eleven potassium bromide ( $\mathrm{KBr}$ ) pellets were prepared with the MP particles (KBr-MP) (labeled P1 to P11). Six KBr-MP pellets (P1, P2, P4, P6, P9 and P11) and three individual particles (P12, P13 and P14) were used for the Raman analyses. The samples were analyzed using a Shimadzu FTIR Prestige-21 spectrometer. Mid-infrared (MIR) absorption spectra were obtained with a resolution of $4 \mathrm{~cm}^{-1}$ in the spectral region of 4000 to $400 \mathrm{~cm}^{-1}$ with 64 scans. Raman spectra were obtained using a Bruker Senterra Raman microscope with a charge-coupled device (CCD) detection system. For each spectrum, 10 accumulations of $10 \mathrm{~s}$, laser with a wavelength of $785 \mathrm{~nm}, \mathrm{a} \times 50$ objective and resolution of about $3 \mathrm{~cm}^{-1}$ were used. Thermal analysis was performed in samples P1, P2, P5 and P7 using a DSC-50 calorimeter (TA Instruments). The samples were cooled from $25^{\circ} \mathrm{C}$ to $-100{ }^{\circ} \mathrm{C}$ and then heated to $400{ }^{\circ} \mathrm{C}$. The cooling and heating ramps were conducted at a rate of $10^{\circ} \mathrm{C} \mathrm{min}^{-1}$ in a nitrogen atmosphere with a flow of $40 \mathrm{~mL} \mathrm{~min}^{-1}$. For processing and identification, all spectra were normalized and baseline-corrected and some Raman spectra were smoothed using specific software (Wiley's KnowltAll + IR \& Raman Libraries).

\section{Results}

\subsection{Morphological characterization of MPs}

Stereoscopic microscopy enabled the visual identification of particles based on texture and "synthetic" appearance. A total of 619 particles were suspected to be MPs and were morphologically characterized according to shape, color and size. Particles were identified with suspicion of being nylon/polyamide $(\mathrm{PA})$, polystyrene (PS), tire rubber, polyethylene (PE), polypropylene (PP) and polyvinyl chloride (PVC) (Fig. 2). The MP particles were classified by shape using the categories proposed by Anger et al. (2018) 
and Silva et al. (2018) - fibers or lines, fragments, films, foam, pellets and sheets (Fig. 3). Particles with different colors were found (blue, light blue, red, transparent, dark green, black, yellow, white, white-yellow and faint yellow) (Fig. 2). The most abundant particles were dark green fibers (22\%), followed by transparent fibers $(15.1 \%)$. A similar number was found of blue fibers and blue fragments $(11 \%$ and $13.3 \%$, respectively). White and black fragments accounted for $6.2 \%$ and $6.8 \%$ of the particles, respectively. Size ranged from $4 \mu \mathrm{m}$ to $5 \mathrm{~mm}$. The distribution of the MPs according to shape and size is illustrated in Figure 4. Thirty-six percent of the particles were smaller than $500 \mu \mathrm{m}$. The range between 500 and $1000 \mu \mathrm{m}$ accounted for the lowest percentage of particles $(12.8 \%) ; 33.3 \%$ were in the range between 1000 and $2000 \mu \mathrm{m}$ and the largest particles (> $2000 \mu \mathrm{m})$ accounted for $17.9 \%$ of the total.

\subsection{Chemical characterization of MPs by Fourier-transform infrared spectroscopy, Raman spectroscopy and differential scattering calorimetry}

As MPs are plastic blends and there are no pure polymeric compounds, the reliable determination of the chemical composition is difficult to achieve using a single technique. Thus, complementary methods are needed for an adequate interpretation [29]. The particles were confirmed as MPs through comparisons to the reference spectra from the polymer library of Wiley's KnowltAll Software with IR \& Raman Spectral database and other spectra from different studies. In the FTIR and Raman spectra, the main bands from the characteristic groups of the components enabled the identification of different plastic materials. Based on the properties and characteristics of the material, the suspected MP particles were from different groups of polymers, such as resins, thermoplastic elastomers (TPEs), olefinic thermoplastics (OTPs), thermoplastic rubber (TPR), cellulose blends and textile fibers.

The FTIR and Raman analyses indicated the particles from sample P1 (which visually looked like PVC) to be possible fragments of an alkyd resin composed of phthalic acid modified with polystyrene. The DSC suggested the same result through a glass transition temperature $\left(T_{g}\right)$ of $20^{\circ} \mathrm{C}$, which is characteristic of an alkyd resin. The spectroscopic analyses also suggested the presence of PE and PP, both of which are considered olefinic thermoplastics (OTPs). The particles in sample P2 were considered PP due to their rigid texture but were identified by FTIR and DSC as PE. DSC showed a predominance of high-density polyethylene (HDPE), as an endothermic peak was observed with a melting temperature $\left(T_{f}\right)$ of $143^{\circ} \mathrm{C}$. In the Raman analysis of sample P2, copper phthalocyanine (CuPc) pigment, also known as pigment blue 15 (PB15), was identified. White fragments from sample P10 were identified as PE by FTIR and the blue fiber from sample P14 was identified as PP by Raman analysis. FTIR analysis of the fragments from sample P3 suggested the presence of a TPE known as poly (EPDM) G-polyamide-6, which is a mixture of polyamide 6 (PA6 [better known as "nylon"]) and an elastomer of the monomer of ethylene-propylenediene (EPDM), and Raman analysis exhibited fluorescence. Sample P8 had a high probability of being a blend of PA and cellulose. Both FTIR and DSC analyses of sample P5 suggested the presence a composite formed by HDPE and cellulose. In the DSC analyses, a peak with a $T_{f}$ at $133^{\circ} \mathrm{C}$ and an exothermic peak around $360^{\circ} \mathrm{C}$ were observed, which are characteristic of HDPE and cellulose, 
respectively. However, a $\mathrm{T}_{g}$ around $44^{\circ} \mathrm{C}$ and a $\mathrm{T}_{\mathrm{f}}$ around $258^{\circ} \mathrm{C}$ were also observed. In both samples P5 and P8, Raman analyses only showed fluorescence. The FTIR analysis indicated sample P4, which was yellow in color with appearance of a paint or worn protective coating for watercraft, to be a synthetic polyurethane-based resin. The Raman analysis of the same sample suggested a yellow, acetoacetic arylide-type monoazo pigment, commercially known as PY74, but the identity of the polymer was also masked by the pigment. Thermoplastic rubber elastomers (TPRs) were also found. FTIR analyses showed a predominance of rubber particles, indicating that samples P6 and P11 were tire rubber and that sample P7 was a different type of white rubber compound. The Raman spectra of samples P6 and P11 identified carbon black pigment, which is a tire reinforcement filler. DSC analysis of P7 suggested the presence of rubber and PP material, as different $\mathrm{T}_{\mathrm{g}}$ were found at approximately $-50^{\circ} \mathrm{C}$ and $-18{ }^{\circ} \mathrm{C}$ and another one at approximately $8{ }^{\circ} \mathrm{C}$, in addition to an endothermic peak with a $T_{f}$ at $171^{\circ} \mathrm{C}$. Fragments from sample P9 were visually suspected to be polystyrene (PS) foam, commercially known as Styrofoam, due to their texture and appearance, which was confirmed by FTIR and Raman analyses and comparisons to the PS reference spectrum. Lastly, the particles from samples P12 and P13 were identified as textile fibers, as Raman analyses determined that both samples were polyester fibers, specifically polyethylene terephthalate (PET).

\section{Discussion}

\subsection{Morphological characterization of MPs}

Determining the size of MPs is essential, since smaller particles have a larger available surface area and therefore have greater capacity to absorb and pre-concentrate organic pollutants from the environment [30]. Moreover, the exposure of MPs to weather leads to a change in the surface color (from white to yellow or black) and is therefore an indication of residence time in the environment [16]. The color change is attributed to the oxidation of phenolic additives in quinone-type products or oxidation of the MPs themselves [31]. Most particles in the present study had their original colors, denoting a relatively short residence time in the water and suggesting recent inputs. However, further research on changes related to weathering and bio-encrustation in aged MP samples is necessary for the discovery of aspects such as the origin, transport and destination of these MPs in the environment [32]. The morphology of the MPs varied and had similarities with particles described in previous studies conducted in Brazil regardless of the coastal ecosystem or biota analyzed. This suggests that the sources of this plastic debris in the marine environment are the same and that water systems may be a primary source of accumulation of these MPs. According to Cavalcante et al. (2020), the coast of the city of Fortaleza receives debris from human activities (recreation, navigation/fishing, domestic and industrial/port activities). This debris is transported by water through urban river systems and can subsequently be transported and dispersed over long distances by winds and ocean currents [23]. Garcia et al. (2020) reported the occurrence of high densities of MPs in highly urbanized locations (such as the metropolitan region of Fortaleza), large fishing areas and tropical estuaries [33]. Standardization among studies is needed for a systematic 
examination of areas of accumulation to gain a better understanding the distribution of MPs in the environment [34].

\subsection{Chemical characterization of MPs}

FTIR spectroscopy is effective at discriminating paints based on different types of resin, but not discriminating resins prepared with similar constituents mixed in different proportions, which makes it difficult to identify many alkyd compounds by FTIR [35]. However, when complemented with Raman spectroscopy, it was possible to infer that sample P1 was an alkyd resin composed of phthalic acid modified with polystyrene (SI-1). The identification of styrene is supported by the presence of bands at $3059,3026,1952,1458,1375,1153,1020,876,700$ and $538 \mathrm{~cm}^{-1}[36,37]$. Furthermore, the bands at $1271 \mathrm{~cm}^{-1}$ and $1724 \mathrm{~cm}^{-1}$ are characteristic of the ester group and the band at $729 \mathrm{~cm}^{-1}$ represents the aromatic ring of the phthalate group [37]. The two bands at 2920 and $2849 \mathrm{~cm}^{-1}$ are due to the stretching of $-\mathrm{CH}_{2}$ groups [36]. The bands at 1103 and $1020 \mathrm{~cm}^{-1}$ can also be attributed to the presence of silica, which is added as a chain extender in many resin compounds [38, 39]. The FTIR results are displayed in Table SI-2.

In agreement with the FTIR results, the Raman spectrum enabled the identification of the main bands of the ester group and polystyrene in addition to the characteristic bands of titanium dioxide $\left(\mathrm{TiO}_{2}\right)$ in the composition of the alkyd resin ( $\mathrm{SI}-1) . \mathrm{TiO}_{2}$ is added to various polymers as a filler, pigment and a UV blocker and was clearly identified in the Raman spectrum due to its three intense characteristic bands at $608,443,226 \mathrm{~cm}^{-1}[11,40]$. The bands attributed to alkyd resin are well established. Phthalate exhibits a low intensity band at $1032 \mathrm{~cm}^{-1}$, whereas styrene has an intense medium band at $1002 \mathrm{~cm}^{-1}$, ester groups exhibit a band at $1727 \mathrm{~cm}^{-1}$ and the phenyl group exhibits a band at $1613 \mathrm{~cm}^{-1}$ [35]. The bands of the fatty acids at 1300 and $1460 \mathrm{~cm}^{-1}$ and the resin groups between 3500 and $2800 \mathrm{~cm}^{-1}$ were masked by the high fluorescence of the inorganic material $\left(\mathrm{TiO}_{2}\right)$, which overpowers the weaker bands of the alkyd resin [37]. The Raman spectrometric results are displayed in Table SI-2.

The DSC analysis revealed a pronounced glass transition temperature $\left(\mathrm{T}_{\mathrm{g}}\right)$ at approximately $20^{\circ} \mathrm{C}$, which is considered the $T_{g}$ of a cured alkyd resin that contains ricinoleic acid in its composition [41]. This findinig is in agreement with the spectroscopic analyses. However, the degradation processes of cured materials are complex and their thermal stability also increases with the degree of branching of alkyd groups in addition to curing time, increasing the $\mathrm{T}_{\mathrm{g}}[41]$. The calorimetric curve (SI-1) shows an endothermic peak with a melting temperature $\left(T_{f}\right)$ of $117^{\circ} \mathrm{C}$, which is related to $L D P E$, but no relationship was found between alkyd resin and LDPE. Therefore, it could have been adhered to the resin particle. Alkyd resins are synthetic polyester polymers widely used in the manufacturing of organic paints, varnishes and lacquers [42, 43] as well as to protect metals from corrosion [44]. Alkyd resins have high strength, durability and compatibility, but dry relatively slowly compared to other synthetic resins and modifications are therefore performed with styrene to accelerate the drying process [45]. The addition of PS confers water repellency to the compound [46]. Thus, one may infer that one of the main source of 
these MPs in the study area is the protective coating found on watercraft, which is subject to wear and abrasion when in contact with water.

In the FTIR spectrum of samples P2 and P10, the main absorption bands (SI-3) and comparisons to the reference spectrum from Wiley's KnowltAll library as well as other studies enabled the identification of PE. These bands are $2920,2851,1468,721 \mathrm{~cm}^{-1}[36,47]$. The characteristic band at $1374 \mathrm{~cm}^{-1}$ (more representative for sample P2 than P10) enabled differentiating low-density PE (LDPE) from high-density polyethylene (HDPE), as the band corresponds to the bending vibration of the methyl group, which is more abundant in highly branched LDPE [47]. Thus, the findings indicate that sample P2 sample is LDPE and sample P10 is HDPE. The bands at 3423,1711 and $1643 \mathrm{~cm}^{-1}$ indicate hydroxyl (O-H), carbonyl $(C=0)$ and $C=C$ bonds, respectively, which may be related to material degradation processes [48]. The hydroxyl group can also appear due to the presence of moisture during the measurement. The carbonyl band may be related to the oxidation of MPs due to the high availability of oxygen to which the particles would be exposed as a result of weathering [49]. The bands at 1165 and $1032 \mathrm{~cm}^{-1}$ may be related to the degradation process [48] as well as the presence of silicon-based compounds, which are widely used as additives in the manufacturing of polymeric materials [38]. The spectrum of sample P10 (SI-3) also had a band at $860 \mathrm{~cm}^{-1}$, which was not observed in sample P2, suggesting a degradation process or a type of cross-linked PE [50]. Degradation processes cause changes in the "characteristic" band of LDPE at 1374 $\mathrm{cm}^{-1}$ and may also appear in HDPE, making it difficult to identify the types of PE. The FTIR results are displayed in Table SI-4. However, the calorimetric curve of sample P2 (SI-3) showed a predominance of HDPE, as an endothermic peak was observed with a $T_{f}$ at $143^{\circ} \mathrm{C}$ (characteristic of HDPE), which may have been displaced from the mean value (approx. $130^{\circ} \mathrm{C}$ ) [28]. This can occur due to degradation processes, which exert an influence on the length of PE chains and molecular weight distributions or can degrade amorphous phases, resulting in high crystallinities [51]. Furthermore, the $T_{f}$ depends on the density of the material, as materials with greater density have a higher melting temperature [52]. In DSC analysis, HDPE can be differentiated from LDPE based on its higher melting temperatures resulting from its greater degree of branching [28].

The Raman analysis of sample P2 (SI-3) enabled the identification of copper phthalocyanine pigment (CuPc), also known as pigment blue 15 (PB15). CuPc is a polycyclic synthetic organic pigment widely used in coatings and paints and has three different polymorphic modifications: alpha (PB15:1), beta (PB15:3 and PB15:4) and epsilon (PB15:6) [53]. Due to the characteristics and intensities of the bands, the sample has high probability of being CuPc with a polymorphic beta modification (PB15:3). The spectral range from 100 to $1800 \mathrm{~cm}^{-1}$ is the most important for the identification of organic pigments $[54,55]$. In the Raman spectrum of CuPc, the bands between 100 and $1000 \mathrm{~cm}^{-1}$ are due to macrocycle vibrations, the band at $953 \mathrm{~cm}^{-1}$ is attributed to the aromatic bending vibration of benzene, the band at $1107 \mathrm{~cm}^{-1}$ is due to the bending vibration in the isoindole group, bands at 1143 and $1341 \mathrm{~cm}^{-1}$ correspond to the pyrrole group and bands between 1350 and 1550 are characteristic of bonds between phthalocyanines and different metal ions (in this case, copper) [53]. It is important to point out that it was impossible to check bands between 200 and $500 \mathrm{~cm}^{-1}$ in the Raman spectrum due to the saturation of 
the detector (CCD) in this region. The Raman spectrometric findings are displayed in Table SI-4. The presence of pigments masks the identity of the polymer, making identification difficult and leading to mistaken conclusions. This is a common problem, especially with dark pigments, such as blue and black [56]. The peaks of the CuPc overlapped the main PE peaks, which is why PE was not identified by Raman spectrometry. It was possible to confirm that sample P2 had a combined spectrum of PE + CuPc [57]. Measures such as increasing the beam wavelength or making multiple measurements by changing the beam contact point with the sample can help solve the problem [56]. Raman spectroscopic analysis of sample P14 sample identified the blue fiber as PP (SI-5), which was compared to the database of Raman spectra of aged MPs [58] and spectra from other studies [40, 59]. However, the interval between 2000 and $1050 \mathrm{~cm}^{-1}$ had high fluorescence, which nearly masked the peaks in this region. Characteristic bands of PP found were at $809,841,973,999,1152,1170,1221,1434$ and $1458 \mathrm{~cm}^{-1}[60,61]$ as well as the range between 2780 and $2980 \mathrm{~cm}^{-1}$ [11]. The bands at 809 and $841 \mathrm{~cm}^{-1}$ are specific to PP due to the helical chains [59]. The Raman spectroscopic findings are displayed Table SI-6. PE and PP are low-cost polymers with easy processing and high production [7]. PE is widely used in the production of food packaging, reusable bags, trays, containers and household items. PP is used in the production of food packaging, household appliances, rope, rigging, belts, automotive parts, etc. [3]. These plastics are quickly discarded, which leads to their greater presence in environmental samples.

The FTIR spectrum of the white fragments from sample P3 (SI-7) shows the main bands of PA6 (nylon) with EPDM rubber. The main bands attributed to the EPDM elastomer are 2918, 2849, 1462, 1379 and $714 \mathrm{~cm}^{-1}$ [62] and the main bands of nylon are at 1643, 1551 and $1267 \mathrm{~cm}^{-1}$ [47]. The bands at 1462 and $1379 \mathrm{~cm}^{-1}$, which were attributed to the EPDM elastomer, could also be attributed to nylon [47]. The bands at 1726 and $1043 \mathrm{~cm}^{-1}$ may be related to polymer oxidation, the intensity of which varies depending on the aging time. The band at $3431 \mathrm{~cm}^{-1}$ suggests the presence of moisture in the medium or oxidation of the polymer [63]. The FTIR findings are displayed in Table SI-8. The PA6 and EPDM blend is considered a TPE and exhibits simultaneous thermoplastic and elastomeric properties [64]. The addition of compatible elastomer copolymers to PA materials has recently been studied to give these materials elastomeric properties and improve their impact resistance and ductility [65]. For such, the most commonly used elastomer is an EPDM terpolymer [64]. PAs are one of the most common engineering thermoplastics and are used in automotive parts, fibers, textiles, films, coatings, industrial machinery and packaging. Other specialized uses include the manufacturing of propellers for marine vessels [64]. In the spectrum of sample P8, which was a PA-cellulose blend (SI-9), the bands at $3273,2920,2857,1645$, $1557,1460,1377$ and $708 \mathrm{~cm}^{-1}$ were assigned to the PA [47]. Cellulose has numerous hydroxyl groups and repetitive cellobiose units, which comprise two glucopyranose rings linked by a glycosidic bond [66]. The bands that enabled the characterization of cellulose were at 3439 and $1315 \mathrm{~cm}^{-1}$, between 1157 and $901 \mathrm{~cm}^{-1}$ [66] as well as between 847 and $600 \mathrm{~cm}^{-1}$ [67]. The FTIR findings are displayed in Table SI-10.

The FTIR spectral analysis of sample P5 (HDPE-cellulose) (SI-11) was compared to the reference spectrum from Wiley's KnowltAll database. The main bands that indicate the presence of HDPE were those at 2920, 2853 and $1464 \mathrm{~cm}^{-1}$, the low intensity band at $1375 \mathrm{~cm}^{-1}$ of both HDPE and cellulose and 
a small band close to $710 \mathrm{~cm}^{-1}$, which was nearly masked by the cellulose bands in this region [68]. The main bands indicating cellulose were those at 3395, 1423, 1375 and $1327 \mathrm{~cm}^{-1}$, the most prominent bands between 1155 and $897 \mathrm{~cm}^{-1}$ [66] and those between 858 and $600 \mathrm{~cm}^{-1}$ [67]. The FTIR findings are displayed in Table SI-12. The thermal analysis showed a certain degree of agreement with the FTIR spectrum, revealing a mixture of polymers (in this case, HDPE and cellulose) (SI-11). The peak with a $\mathrm{T}_{\mathrm{f}}$ at $133^{\circ} \mathrm{C}$ is characteristic of HDPE and an exothermic peak was found around $360^{\circ} \mathrm{C}$ due to the oxidative degradation of cellulose $[67,69]$. It is possible that an endothermic peak (cellulose decomposition) was masked by the exothermic peak (oxidative degradation), with both events occurring simultaneously [67]. However, a $\mathrm{T}_{\mathrm{g}}$ around $44^{\circ} \mathrm{C}$ and $\mathrm{a} \mathrm{T}_{\mathrm{f}}$ around $258^{\circ} \mathrm{C}$ were also observed, which are characteristic of a PA [28]. As some FTIR characteristic bands of HDPE are similar to some characteristic bands of PA, these could have been confused or the HDPE, PA and cellulose could have been mixed. Repeated analyses or a more specific analysis could help clarify this issue. Both the FTIR and DSC analyses of sample P5 (SI-11) suggest the presence of HDPE and cellulosic material, the latter of which is used as a reinforcing filler for plastic materials, forming a composite. As reported in previous studies, HDPE is among the most widely used thermoplastics as a matrix for composites reinforced with cellulose, which enables enhancing the mechanical properties [70]. Coupling agents, such as isocyanates and silanes, are normally used to obtain better adhesion of the matrix to the reinforcement material, which also helps improve the mechanical properties of the composite [70]. Plant fibers, such as cellulose, have the potential to reinforce polymeric materials due to their good mechanical and thermal properties, biodegradability and lower cost compared to other traditional reinforcement materials, such as fiberglass, talcum or mica $[67,70,71]$.

The FTIR spectrum of sample P4 (SI-13) revealed characteristic bands of PU resin. However, as a commercial material with varied composition, PU-based resins include several systems with different properties, which increases the complexity of material identification. Indeed, the composition of PU comprises polyols, diisocyanate and chain extenders as possible chemical precursors [38]. Hexamethylene diisocyanate $(\mathrm{HDI})$ is one of the most common monomeric aliphatic diisocyanates used in PU coatings and polyols contain ester, ether, amide and acrylic groups in their structure, which can also influence absorption bands in FTIR [38, 72]. Other compounds that can be added to PU resins include solvents (esters, ketones and ethers), chain extenders (barites, calcium carbonate, talc, mica and silica) as well as inorganic or organic pigments [38]. The bands at 2920 and $2853 \mathrm{~cm}^{-1}$ correspond to the presence of $\mathrm{HDI}$. The band at $1730 \mathrm{~cm}^{-1}$ is due to ester and/or acrylic groups (most likely the acrylate group due to the presence of other characteristic bands) of the polyol used in resin manufacturing [38]. The band at $1639 \mathrm{~cm}^{-1}$ is attributed to the urethane group [38,39] and the band at $1520 \mathrm{~cm}^{-1}$ may be related to a secondary amide of the urethane group. The band at $1458 \mathrm{~cm}^{-1}$ is attributed to the HDI monomer. The band at $1267 \mathrm{~cm}^{-1}$ is related to urethane and acrylate groups [38, 39]. The band at 1123 $\mathrm{cm}^{-1}$ is related to the acrylate group. The band at $1065 \mathrm{~cm}^{-1}$ is due to urea and acrylate groups [39], but may also be attributed to the presence of crystalline silica, with bands at 1032 and $787 \mathrm{~cm}^{-1}$. The band at $739 \mathrm{~cm}^{-1}$ may be related to the HDI isocyanurate skeleton [38]. The FTIR findings are displayed in Table SI-14. In the Raman spectrometric analysis of the same sample (SI-13), polymer masking also 
occurred due to the presence of the pigment, as occurred above with PE being masked by CuPc. The characteristics and band intensities in the region between 1000 and $1700 \mathrm{~cm}^{-1}$ indicate the acetoacetic arylide-type monoazo yellow pigment, which is commercially known as PY74 [54]. Defeyt et al. (2017) also mentioned the use of yellow monoazo pigments in PU-based paint formulations [38]. Peaks in the spectral region between 1000 and $200 \mathrm{~cm}^{-1}$ were due to fluorescence. Recently, several urethane-based coatings and high modulus polyurethane varnishes have been used in furniture and marine applications [64]. These coatings are suitable for outdoor and marine uses, such as wood finishes on boats due to their good weather resistance [42]. Therefore, PUs likely enter the marine environment in the same way as alkyd resins.

The main bands of samples P6, P7 and P11 characterized rubber compounds when the FTIR spectra (SI15) were compared to rubber spectra from other studies $[29,73,74]$. The bands in the region between 1500 and $800 \mathrm{~cm}^{-1}$ are attributed to the elastomeric components $\mathrm{SiO}_{2}$ and carbon black, whereas bands in the region between 800 and $400 \mathrm{~cm}^{-1}$ correspond to sulfur bonds [75]. The following bands were observed: 2955, 2920, 2849, 1464 and $1375 \mathrm{~cm}^{-1}$. A band around $1548 \mathrm{~cm}^{-1}$ also appeared, which may be attributed to $C=C$ stretching [73] or the $C$-S bond in vulcanized rubber [74]. The band at $1259 \mathrm{~cm}^{-1}$ has two possible attributions: the out-of-plane angular deformation of the $-\mathrm{CH}_{2}$ group [73] or $\mathrm{C}-\mathrm{O}$ stretching due to the zinc stearate ester group formed during vulcanization [76]. The band at $1158 \mathrm{~cm}^{-1}$ corresponds to thioamide formed by the presence of the vulcanization accelerator tetramethylthiuram monosulfide (TMTM) [76]. The wide band at $1038 \mathrm{~cm}^{-1}$ is attributed to carbon black and the band at 721 $\mathrm{cm}^{-1}$ results from the out-of-plane deformation of $-\mathrm{C}=\mathrm{C}-\mathrm{H}$ [75]. The FTIR findings are displayed in Table SI-16. Regarding the Raman spectrum (SI-15), only two broad bands were identified at 1579 and 1336 $\mathrm{cm}^{-1}$ in samples P6 and P11, which are assumed to be due to $\mathrm{C}-\mathrm{C}$ stretching of the carbon black in the rubber composition $[40,56]$. The Raman spectrometric findings are displayed in Table SI-16. Carbon black is added to tire at a proportion of 22 to $40 \%$ as a reinforcing filler and to make the tire UV resistant [77]. In the present analyses, its high content masks the identity of the rubber polymer, which constitutes a problem in the identification of dark colored rubber particles [56] and hinders spectroscopic methods based on single particle analysis [77].

As the FTIR analysis suggested rubber compounds in sample P7 (SI-15), we can assign $\mathrm{T}_{\mathrm{g}}$ at $-50^{\circ} \mathrm{C}$ to these compounds and $\mathrm{T}_{\mathrm{g}}$ at -18 and $8{ }^{\circ} \mathrm{C}$ and $\mathrm{T}_{\mathrm{f}}$ at $171^{\circ} \mathrm{C}$ to PP in the DSC analysis [42]. PP can have different $\mathrm{T}_{\mathrm{g}}$ values depending on the polymer chain arrangement. Thus, $\mathrm{T}_{\mathrm{g}}$ at $-18{ }^{\circ} \mathrm{C}$ may be related to syndiotactic PP and $\mathrm{T}_{\mathrm{g}}$ at $8{ }^{\circ} \mathrm{C}$ may be related to isotactic PP [42]. The combination of these analyses suggests that sample P7 is an EPM-type or EPDM-type thermoplastic rubber, which have PP in their composition and the $\mathrm{T}_{\mathrm{g}}$ of this type of elastomer is in a range of -30 to $-60^{\circ} \mathrm{C}$, depending on the composition and percentage of PP in the material [78]. However, the presence of another rubber material cannot be not ruled out, since $\mathrm{T}_{\mathrm{g}}$ at $-18{ }^{\circ} \mathrm{C}$ could also be attributed to polybutadiene, which is also used in the manufacturing of thermoplastic rubbers. Furthermore, $\mathrm{T}_{\mathrm{g}}$ at $-50^{\circ} \mathrm{C}$ could be due to styrene-butadiene rubber (SBR), which is compatible with other main elastomers and can be used in mixtures [79]. The 
composition of rubber is varied and these compounds have a wide $T_{g}$ range. Typical tire rubber includes a mixture of natural (polyisoprene) and synthetic (SBR, polybutadiene) rubber, reinforcing filler compounds (carbon black, silica and chalk), softener (oil or resin), vulcanizing agents (sulfur and zinc oxide) and other additives [80, 81]. As thermoplastic rubbers (TPRs) are widely used in the manufacturing of tires, several studies suggest that the wear of automobile tires due to mechanical abrasion from contact with the road surface is an important source of MPs in the environment [77, 82]. Similar wear occurs with bicycle tires, conveyor belts, artificial grass, ground tires, rubber mats and automobile brake pads [77]. Small particles of worn tire are dispersed in the environment mainly by air, whereas larger particles are transported by rainwater runoff, sewage and/or surface water [77].

The FTIR spectrum of sample P9 (SI-17) revealed bands (although not intense) at 3057, 3024, 2920, $2849,1944,1871,1800,1741,1597,1549,1463,1373,1313,1155,1032,908,752,698$ and $542 \mathrm{~cm}^{-1}$ characteristic of PS [36]. The FTIR findings are displayed in Table SI-18. The bands at 3424 and 1711 $\mathrm{cm}^{-1}$ correspond to hydroxyl and carbonyl, respectively, indicating the possible oxidation of weathered PS [49]. The Raman spectrum (SI-17) exhibited high agreement with the PS reference spectrum in previous studies $[59,83]$. The spectral bands suitable for detecting PS are at 1584, 1602, 1002 and $1032 \mathrm{~cm}^{-1}$ [11]. The Raman spectrometric findings are displayed in Table SI-18. PS is an aromatic polymer made of a styrene monomer belonging to the thermoplastic family. Its main application is in packaging (more than half of the market). PS has low biodegradability and is not widely recycled, which increases its persistence in the environment [64].

For samples P12 and P13, the Raman spectrometric analyses (SI-19) determined that both were polyester fibers, specifically polyethylene terephthalate (PET), which was confirmed by comparing the sample spectrum with the PET spectrum of the Raman spectral database created by Dong et al. (2020) as well as spectra described in other studies [84]. The main bands that enabled the identification of PET were at $1725,1613,1291,793$ and $858 \mathrm{~cm}^{-1}[59,85]$. High fluorescence was found in the region from $1375 \mathrm{~cm}^{-1}$ to approximately $1500 \mathrm{~cm}^{-1}$ due to the presence of glass from the microscope slide used in the analysis, which nearly masked a small peak at $1415 \mathrm{~cm}^{-1}$. The Raman spectrometric findings are displayed in Table SI-20. PET is a thermoplastic traditionally used in the production of fibers for textile products and films for food packaging [64]. PET textile fibers are used for the manufacturing of various fabrics, such as clothes, carpets, airbags and bags. Indeed, the demand for polyester exceeded that of cotton in 2002 [86]. Household laundry is a potentially important source for the release of microfibers into aquatic environments $[32,87]$. These fibers enter the marine environment mainly through domestic sewage contaminated with synthetic fibers from the washing of clothes as well as through effluents from wastewater treatment plants $[88,89]$, demonstrating the potentially important role that textiles, laundry and wastewater discharge play in the contamination of oceans by MPs [32].

\section{Conclusion}


The most abundant MP particles found on the coast of the city of Fortaleza, Brazil were fibers and fragments, accounting for 57 and $36.2 \%$, respectively. The importance of the morphological characterization is highlighted in this study, as this characterization can assist in the monitoring of persistent organic pollutants in the marine environment. The MPs were chemically characterized using FTIR and Raman spectrometry as well as differential scanning calorimetry. These methods complement each other very well and are useful for analyzing synthetic polymers with different chemical characteristics. The spectra presented here could serve as a database for future studies on MPs. Particles of PE, PP, PA and PS are believed to enter the marine environment mainly through fishing activities, debris from food packaging, personal care products, single-use packages and other household products. PET and PA (nylon) fibers enter mainly through domestic sewage contaminated by fibers from the washing of clothes, as these compounds are widely used in the manufacturing of fabrics. Alkyd and PU resins likely enter the environment from the abrasive wear of surface coatings on ships, road markings and coatings on commercial buildings, as these compounds are widely used in the manufacturing of paints, varnishes and lacquers. The rubber particles come mainly from the wear of the automobile tires as well as roofs, asphalt, automobile brake pads, etc. The main dispersal routes of these MP particles in the environment are the wind, currents, storms, rainwater runoff, sewage and surface water. Thus, one may infer that the main sources of MPs in the marine environment on the coast of Fortaleza are human activities. However, these sources require more exhaustive research.

\section{References}

1. R. Geyer, J.R. Jambeck, K.L. Law, Production, use, and fate of all plastics ever made, Sci. Adv. 3 (2017) 1-5. https://doi.org/10.1126/sciadv.1700782.

2. W. de Wit, A. Hamilton, R. Scheer, T. Stakes, S. Allan, Por solucionar a poluição plástica: transparência e responsabilização, Genebra, 2019. https://jornalismosocioambiental.files.wordpress.com/2019/03/plastic_report_02-2019.pdf.

3. G.M.R.C.M.\& S.G. PlasticsEurope, Plastics - the Facts 2019, Brussels, 2019. https://www.plasticseurope.org/en/resources/market-data.

4. S. Kaza, L.C. Yao, P. Bhada-Tata, F. Van Woerden, What a waste 2.0: a global snapshot of solid waste management to 2050, World Bank, Washington, DC, 2018. https://doi.org/10.1596/978-1-4648-13290 .

5. C.G. Avio, S. Gorbi, F. Regoli, Plastics and microplastics in the oceans: from emerging pollutants to emerged threat, Mar. Environ. Res. 128 (2017) 2-11. https://doi.org/10.1016/j.marenvres.2016.05.012.

6. B. Gewert, M.M. Plassmann, M. MacLeod, Pathways for degradation of plastic polymers floating in the marine environment, Environ. Sci. Process. Impacts. 17 (2015) 1513-1521. https://doi.org/10.1039/C5EM00207A.

7. S. V. Canevarolo Jr, Ciência dos polímeros: um texto básico para tecnólogos e engenheiros, 2nd ed., Artliber Editora Ltda., São Paulo, 2006. 
8. A.L. Andrady, Microplastics in the marine environment, Mar. Pollut. Bull. 62 (2011) 1596-1605. https://doi.org/10.1016/j.marpolbul.2011.05.030.

9. R.C. Thompson, Lost at sea: where is all the plastic?, Science (80-.). 304 (2004) 838-838. https://doi.org/10.1126/science.1094559.

10. C. Arthur, J. Baker, H. (eds.. Bamford, Proceedings of the international research workshop on the occurrence, effects, and fate of microplastic marine debris, Washington, DC, 2009. (accessed August 11, 2021).

11. A. Käppler, D. Fischer, S. Oberbeckmann, G. Schernewski, M. Labrenz, K.J. Eichhorn, B. Voit, Analysis of environmental microplastics by vibrational microspectroscopy: FTIR, Raman or both?, Anal. Bioanal. Chem. 408 (2016) 8377-8391. https://doi.org/10.1007/s00216-016-9956-3.

12. P.M. Anger, E. von der Esch, T. Baumann, M. Elsner, R. Niessner, N.P. Ivleva, Raman microspectroscopy as a tool for microplastic particle analysis, TrAC - Trends Anal. Chem. 109 (2018) 214-226. https://doi.org/10.1016/j.trac.2018.10.010.

13. H.. Auta, C.. Emenike, S.. Fauziah, Distribution and importance of microplastics in the marine environment: a review of the sources, fate, effects, and potential solutions, Environ. Int. 102 (2017) 165-176. https://doi.org/10.1016/j.envint.2017.02.013.

14. M. Cole, P. Lindeque, C. Halsband, T.S. Galloway, Microplastics as contaminants in the marine environment: a review, Mar. Pollut. Bull. 62 (2011) 2588-2597. https://doi.org/10.1016/j.marpolbul.2011.09.025.

15. R.L. Coppock, M. Cole, P.K. Lindeque, A.M. Queirós, T.S. Galloway, A small-scale, portable method for extracting microplastics from marine sediments, Environ. Pollut. 230 (2017) 829-837. https://doi.org/10.1016/j.envpol.2017.07.017.

16. E.L. Teuten, J.M. Saquing, D.R.U. Knappe, M.A. Barlaz, S. Jonsson, A. Björn, S.J. Rowland, R.C. Thompson, T.S. Galloway, R. Yamashita, D. Ochi, Y. Watanuki, C. Moore, P.H. Viet, T.S. Tana, M. Prudente, R. Boonyatumanond, M.P. Zakaria, K. Akkhavong, Y. Ogata, H. Hirai, S. Iwasa, K. Mizukawa, Y. Hagino, A. Imamura, M. Saha, H. Takada, Transport and release of chemicals from plastics to the environment and to wildlife, Philos. Trans. R. Soc. B Biol. Sci. 364 (2009) 2027-2045. https://doi.org/10.1098/rstb.2008.0284.

17. X. Guo, J. Wang, The chemical behaviors of microplastics in marine environment: a review, Mar. Pollut. Bull. 142 (2019) 1-14. https://doi.org/10.1016/j.marpolbul.2019.03.019.

18. A.B. Silva, A.S. Bastos, C.I.L. Justino, J.P. Da Costa, A.C. Duarte, T.A.P. Rocha-Santos, Microplastics in the environment: challenges in analytical chemistry - a review, Anal. Chim. Acta. 1017 (2018) 1-19. https://doi.org/10.1016/j.aca.2018.02.043.

19. R. Sussarellu, M. Suquet, Y. Thomas, C. Lambert, C. Fabioux, M.E.J. Pernet, N. Le Goïc, V. Quillien, C. Mingant, Y. Epelboin, C. Corporeau, J. Guyomarch, J. Robbens, I. Paul-Pont, P. Soudant, A. Huvet, Oyster reproduction is affected by exposure to polystyrene microplastics, Proc. Natl. Acad. Sci. 113 (2016) 2430-2435. https://doi.org/10.1073/pnas.1519019113. 
20. C. Alomar, F. Estarellas, S. Deudero, Microplastics in the mediterranean sea: deposition in coastal shallow sediments, spatial variation and preferential grain size, Mar. Environ. Res. 115 (2016) 1-10. https://doi.org/10.1016/j.marenvres.2016.01.005.

21. J.G. of E. on the S.A. of M.E.P. GESAMP, Sources, fate and effects of microplastics in the marine environment: part 2 of a global assessment., London, 2016. http://www.gesamp.org/site/assets/files/1275/sources-fate-and-effects-of-microplastics-in-themarine-environment-part-2-of-a-global-assessment-en.pdf.

22. R.O. Castro, M.L. da Silva, F.V. de Araújo, Review on microplastic studies in Brazilian aquatic ecosystems, Ocean Coast. Manag. 165 (2018) 385-400. https://doi.org/10.1016/j.ocecoaman.2018.09.013.

23. R.M. Cavalcante, L.S. Pinheiro, C.E.P. Teixeira, B.P. Paiva, G.M. Fernandes, D.B. Brandão, F.F. Frota, F.J.N. Silva Filho, C.A.F. Schettini, Marine debris on a tropical coastline: abundance, predominant sources and fate in a region with multiple activities (Fortaleza, Ceará, northeastern Brazil), Waste Manag. 108 (2020) 13-20. https://doi.org/10.1016/j.wasman.2020.04.026.

24. R.M. Cavalcante, M.V.F. De Andrade, R. V. Marins, L.D.M. Oliveira, Development of a headspace-gas chromatography (HS-GC-PID-FID) method for the determination of VOCs in environmental aqueous matrices: Optimization, verification and elimination of matrix effect and VOC distribution on the Fortaleza Coast, Brazil, Microchem. J. 96 (2010) 337-343. https://doi.org/10.1016/j.microc.2010.05.014.

25. I.B. de G. e E. IBGE, População estimada, Inst. Bras. Geogr. e Estatística. (2020). https://cidades.ibge.gov.br/brasil/ce/fortaleza/panorama (accessed August 18, 2021).

26. J. Masura, J. Baker, G. Foster, C. Arthur, C. Herring, Laboratory methods for the analysis of microplastics in the marine environment: recommendations for quantifying synthetic particles in waters and sediments, NOAA. (2015) 1-39.

27. H. Bitter, S. Lackner, Fast and easy quantification of semi-crystalline microplastics in exemplary environmental matrices by differential scanning calorimetry (DSC), Chem. Eng. J. 423 (2021) 1-7. https://doi.org/10.1016/j.cej.2021.129941.

28. M. Majewsky, H. Bitter, E. Eiche, H. Horn, Determination of microplastic polyethylene (PE) and polypropylene (PP) in environmental samples using thermal analysis (TGA-DSC), Sci. Total Environ. 568 (2016) 507-511. https://doi.org/10.1016/j.scitotenv.2016.06.017.

29. U. Rozman, T. Turk, T. Skalar, M. Zupančič, N. Čelan Korošin, M. Marinšek, J. Olivero-Verbel, G. Kalčíková, An extensive characterization of various environmentally relevant microplastics material properties, leaching and ecotoxicity testing, Sci. Total Environ. 773 (2021) 1-10. https://doi.org/10.1016/j.scitotenv.2021.145576.

30. A. Menéndez-Pedriza, L. Jaumot, Microplastics: a critical review of sorption factors, Toxics. 8 (2020) 1-40. https://doi.org/doi:10.3390/toxics8020040.

31. Y.K. Song, S.H. Hong, M. Jang, G.M. Han, S.W. Jung, W.J. Shim, Combined effects of UV exposure duration and mechanical abrasion on microplastic fragmentation by polymer type, Environ. Sci. 
Technol. 51 (2017) 4368-4376. https://doi.org/10.1021/acs.est.6b06155.

32. P.S. Ross, S. Chastain, E. Vassilenko, A. Etemadifar, S. Zimmermann, S.-A. Quesnel, J. Eert, E. Solomon, S. Patankar, A.M. Posacka, B. Williams, Pervasive distribution of polyester fibres in the Arctic ocean is driven by Atlantic inputs, Nat. Commun. 12 (2021) 106. https://doi.org/10.1038/s41467-020-20347-1.

33. T.M. Garcia, C.C. Campos, E.M.T. Mota, N.M.O. Santos, R.P. de S. Campelo, L.C.G. Prado, M. Melo Junior, M. de O. Soares, Microplastics in subsurface waters of the western equatorial Atlantic (Brazil), Mar. Pollut. Bull. 150 (2020) 1-6. https://doi.org/10.1016/j.marpolbul.2019.110705.

34. V. Hidalgo-Ruz, L. Gutow, R.C. Thompson, M. Thiel, Microplastics in the marine environment: a review of the methods used for identification and quantification, Environ. Sci. Technol. 46 (2012) 30603075. https://doi.org/10.1021/es2031505.

35. S.E.J. Bell, L.A. Fido, S.J. Speers, W.J. Armstrong, S. Spratt, Forensic analysis of architectural finishes using Fourier transform infrared and Raman spectroscopy, part I: the resin bases, Appl. Spectrosc. 59 (2005) 1333-1339.

36. R. Chércoles Asensio, M.S.A. Moya, J.M. de la Roja, M. Gómez, Analytical characterization of polymers used in conservation and restoration by ATR-FTIR spectroscopy, Anal. Bioanal. Chem. 395 (2009) 2081-2096. https://doi.org/10.1007/s00216-009-3201-2.

37. H.R. Ong, M.M.R. Khan, R. Ramli, M.W. Rahman, R.M. Yunus, Tailoring base catalyzed synthesis of palm oil based alkyd resin through CuO nanoparticles, RSC Adv. 5 (2015) 95894-95902. https://doi.org/10.1039/C5RA19575F.

38. C. Defeyt, J. Langenbacher, R. Rivenc, Polyurethane coatings used in twentieth century outdoor painted sculptures. part I: comparative study of various systems by means of ATR-FTIR spectroscopy, Herit. Sci. 5 (2017) 11. https://doi.org/10.1186/s40494-017-0124-7.

39. L. Passauer, A case study on the thermal degradation of an acrylate-type polyurethane wood coating using thermogravimetry coupled with evolved gas analysis, Prog. Org. Coatings. 157 (2021) 1-12. https://doi.org/10.1016/j.porgcoat.2021.106331.

40. R. Lenz, K. Enders, C.A. Stedmon, D.M.A. MacKenzie, T.G. Nielsen, A critical assessment of visual identification of marine microplastic using Raman spectroscopy for analysis improvement, Mar. Pollut. Bull. 100 (2015) 82-91. https://doi.org/10.1016/j.marpolbul.2015.09.026.

41. M. Jovičić, R. Radičević, J. Pavličević, O. Bera, D. Govedarica, Synthesis and characterization of ricinoleic acid based hyperbranched alkyds for coating application, Prog. Org. Coatings. 148 (2020) 1-14. https://doi.org/10.1016/j.porgcoat.2020.105832.

42. F.W. Billmeyer Jr, Textbook of polymer science, Third, Wiley-Interscience, New York, 1984.

43. H. Nosal, J. Nowicki, M. Warzała, I. Semeniuk, E. Sabura, Synthesis and characterization of alkyd resins based on Camelina sativa oil, glycerol and selected epoxidized vegetable oils as functional modifiers, Prog. Org. Coatings. 101 (2016) 553-568. https://doi.org/10.1016/j.porgcoat.2016.10.003. 
44. M.A. Deyab, G. Mele, A.M. Al-Sabagh, E. Bloise, D. Lomonaco, S.E. Mazzetto, C.D.S. Clemente, Synthesis and characteristics of alkyd resin/M-porphyrins nanocomposite for corrosion protection application, Prog. Org. Coatings. 105 (2017) 286-290. https://doi.org/10.1016/j.porgcoat.2017.01.008.

45. M.H. Swann, Determination of polystyrene in styrenated alkyd and styrenated epoxy resins, Anal. Chem. 25 (1953) 1735-1737. https://doi.org/10.1021/ac60083a039.

46. D. Foti, C. Passialis, E. Voulgaridis, S. Adamopoulos, Water repellency of cellulosic fibrous mats impregnated with organic solutions based on recycled polystyrene, J. Renew. Mater. 9 (2021) 85-96. https://doi.org/10.32604/jrm.2021.011868.

47. M.R. Jung, F.D. Horgen, S. V. Orski, V. Rodriguez C., K.L. Beers, G.H. Balazs, T.T. Jones, T.M. Work, K.C. Brignac, S.J. Royer, K.D. Hyrenbach, B.A. Jensen, J.M. Lynch, Validation of ATR FT-IR to identify polymers of plastic marine debris, including those ingested by marine organisms, Mar. Pollut. Bull. 127 (2018) 704-716. https://doi.org/10.1016/j.marpolbul.2017.12.061.

48. K. Formela, M. Wołosiak, M. Klein, S. Wang, Characterization of volatile compounds, structural, thermal and physico-mechanical properties of cross-linked polyethylene foams degraded thermomechanically at variable times, Polym. Degrad. Stab. 134 (2016) 383-393. https://doi.org/10.1016/j.polymdegradstab.2016.11.011.

49. J. Wang, J. Peng, Z. Tan, Y. Gao, Z. Zhan, Q. Chen, L. Cai, Microplastics in the surface sediments from the Beijiang river littoral zone: composition, abundance, surface textures and interaction with heavy metals, Chemosphere. 171 (2017) 248-258. https://doi.org/10.1016/j.chemosphere.2016.12.074.

50. S.L. de M. Paiva Júnior, S.L.S. de Melo, Estudo do processo de reciclagem do polietileno para produção de blendas, in: 72 Congr. Anu. Da ABM, Editora Edgard Blucher, Ltda., São Paulo, 2017: pp. 879-886. https://doi.org/10.5151/1516-392x-30343.

51. P. Liu, X. Zhan, X. Wu, J. Li, H. Wang, S. Gao, Effect of weathering on environmental behavior of microplastics: properties, sorption and potential risks, Chemosphere. 242 (2020) 125193. https://doi.org/10.1016/j.chemosphere.2019.125193.

52. B.C. Gary, A.M. Costa, A.F. Bragil, W. Costa, Estudo térmico do PEAD e PEBD através de análise térmica differenctial scanning calorimeter (DSC), 2018. https://oswaldocruz.br/revista_academica/content/pdf/Edicao_20_BRUNO_C_GARY.pdf (accessed June 20, 2021).

53. M. Anghelone, D. Jembrih-Simbürger, M. Schreiner, Identification of copper phthalocyanine blue polymorphs in unaged and aged paint systems by means of micro-Raman spectroscopy and Random Forest, Spectrochim. Acta - Part A Mol. Biomol. Spectrosc. 149 (2015) 419-425. https://doi.org/10.1016/j.saa.2015.04.094.

54. N.C. Scherrer, Z. Stefan, D. Francoise, F. Annette, K. Renate, Synthetic organic pigments of the 20th and 21 st century relevant to artist's paints: Raman spectra reference collection, Spectrochim. Acta Part A Mol. Biomol. Spectrosc. 73 (2009) 505-524. https://doi.org/10.1016/j.saa.2008.11.029. 
55. P. Ropret, S.A. Centeno, P. Bukovec, Raman identification of yellow synthetic organic pigments in modern and contemporary paintings: reference spectra and case studies, Spectrochim. Acta Part A Mol. Biomol. Spectrosc. 69 (2008) 486-497. https://doi.org/10.1016/j.saa.2007.03.050.

56. K. Munno, H. De Frond, B. O'donnell, C.M. Rochman, Increasing the accessibility for characterizing microplastics: introducing new application-based and spectral libraries of plastic particles (SLoPP and SLoPP-E), Anal. Chem. 92 (2020) 2443-2451. https://doi.org/10.1021/acs.analchem.9b03626.

57. A. Karami, A. Golieskardi, Y. Bin Ho, V. Larat, B. Salamatinia, Microplastics in eviscerated flesh and excised organs of dried fish, Sci. Rep. 7 (2017) 54-73. https://doi.org/10.1038/s41598-017-05828-6.

58. M. Dong, Q. Zhang, X. Xing, W. Chen, Z. She, Z. Luo, A Raman database of microplastics weathered under natural environments, Sci. Total Environ. 739 (2020) 1-9. https://doi.org/10.17632/KPYGRF9FG6.2.

59. S. Zhao, M. Danley, J.E. Ward, D. Li, T.J. Mincer, An approach for extraction, characterization and quantitation of microplastic in natural marine snow using Raman microscopy, Anal. Methods. 9 (2017) 1470-1478. https://doi.org/10.1039/C6AY02302A.

60. A.S. Nielsen, D.N. Batchelder, R. Pyrz, Estimation of crystallinity of isotactic polypropylene using Raman spectroscopy, Polymer (Guildf). 43 (2002) 2671-2676. https://doi.org/10.1016/S00323861(02)00053-8.

61. R.G. Snyder, J.H. Schachtschneider, Valence force calculation of the vibrational spectra of crystalline isotactic polypropylene and some deuterated polypropylenes, Spectrochim. Acta. 20 (1964) 853869. https://doi.org/10.1016/0371-1951(64)80084-9.

62. R.P. de O. Santos, Compósitos baseados em PET reciclado, fibras de sisal e plasticizantes oriundos de fontes renováveis: estudo do processamento e propriedades destes materiais, Biblioteca Digital de Teses e Dissertações da Universidade de São Paulo, 2012. https://doi.org/10.11606/D.88.2012.tde-26072012-163329.

63. N. Samarth, P. Mahanwar, Study and characterization of LLDPE/polyolefin elastomer and LLDPE/EPDM blend: effect of chlorinated water on blend performance, Mater. Today Proc. 5 (2018) 22433-22446. https://doi.org/10.1016/j.matpr.2018.06.613.

64. J.A. Brydson, Brydson's plastics materials, 8th ed., Matthew Deans, Oxford, 2017. https://doi.org/10.1016/C2014-0-02399-4.

65. G.M.O. Barra, J. Roeder, V. Soldi, A.T.N. Pires, J.A.M. Agnelli, Blendas de poliamida 6/elastômero: propriedades e influência da adição de agente compatibilizante, Polímeros. 13 (2003) 95-101. https://doi.org/10.1590/S0104-14282003000200006.

66. C. Schramm, High temperature ATR-FTIR characterization of the interaction of polycarboxylic acids and organotrialkoxysilanes with cellulosic material, Spectrochim. Acta Part A Mol. Biomol. Spectrosc. 243 (2020) 118-815. https://doi.org/10.1016/j.saa.2020.118815.

67. G.S. Silva, Preparação e caracterização de tecidos tratados com polianilina condutora recobertas com borracha natural, Universidade Estadual Paulista (UNESP), 2007. https://repositorio.unesp.br/handle/11449/88459 (accessed June 16, 2021). 
68. A. Dönmez Çavdar, E.D. Tomak, S. Boran Torun, S.S. Arpaci, Accelerated weathering resistance of high-density polyethylene composites reinforced with microcrystalline cellulose and fire retardants, J. Build. Eng. 39 (2021) 1-9. https://doi.org/10.1016/j.jobe.2021.102282.

69. S. Tsujiyama, A. Miyamori, Assignment of DSC thermograms of wood and its components, Thermochim. Acta. 351 (2000) 177-181. https://doi.org/10.1016/S0040-6031(00)00429-9.

70. A.K.K. Bledzki, J. Gassan, Composites reinforced with cellulose based fibres, Prog. Polym. Sci. 24 (1999) 221-274. https://doi.org/10.1016/S0079-6700(98)00018-5.

71. D. Puglia, J. Biagiotti, J.M. Kenny, A review on natural fibre-based composites-part II, J. Nat. Fibers. 1 (2005) 23-65. https://doi.org/10.1300/J395v01n03_03.

72. D.K. Chattopadhyay, K.V.S.N. Raju, Structural engineering of polyurethane coatings for high performance applications, Prog. Polym. Sci. 32 (2007) 352-418. https://doi.org/10.1016/j.progpolymsci.2006.05.003.

73. A.C. Dall'Antonia, M.A. Martins, R.M.B. Moreno, L.H.C. Mattoso, P.S. Gongalves, A.E. Job, Mechanical and thermal characterization of compounds of natural rubber of the clones: GT 1, IAN 873, PB 235 and RRIM 600, Polim. Ciência e Tecnol. 19 (2009) 63-71. https://doi.org/10.1590/s010414282009000100015.

74. F. Karabork, E. Pehlivan, A. Akdemir, Characterization of styrene butadiene rubber and microwave devulcanized ground tire rubber composites, J. Polym. Eng. 34 (2014) 543-554. https://doi.org/10.1515/polyeng-2013-0330.

75. X. Colom, A. Faliq, K. Formela, J. Cañavate, FTIR spectroscopic and thermogravimetric characterization of ground tyre rubber devulcanized by microwave treatment, Polym. Test. 52 (2016) 200-208. https://doi.org/10.1016/j.polymertesting.2016.04.020.

76. R.P. dos Santos, M.S. de O. Junior, E. da C. Mattos, M.F. Diniz, R. de C.L. Dutra, Caracterização por FTIR da superfície de borracha EPDM tratada via plasma por micro-ondas, Polímeros. 22 (2012) 440446. https://doi.org/10.1590/S0104-14282012005000065.

77. P.J. Kole, A.J. Löhr, F. Van Belleghem, A. Ragas, Wear and tear of tyres: a stealthy source of microplastics in the environment, Int. J. Environ. Res. Public Health. 14 (2017) 1-31. https://doi.org/10.3390/ijerph14101265.

78. R.T. Sataloff, M.M. Johns, K.M. Kost, Developments in rubber technology-2: synthetic rubbers, 1 st ed., APPLIED SCIENCE PUBLISHERS LTD, London, 1981. https://doi.org/10.1007/978-94-009-8108-9.

79. M. Morton, Rubber Technology, 3rd ed., Springer US, Boston, 1987. https://doi.org/10.1007/978-14615-7823-9.

80. B. Baensch-Baltruschat, B. Kocher, F. Stock, G. Reifferscheid, Tyre and road wear particles (TRWP) - a review of generation, properties, emissions, human health risk, ecotoxicity, and fate in the environment, Sci. Total Environ. 733 (2020) 1-19. https://doi.org/10.1016/j.scitotenv.2020.137823.

81. C.H. Scuracchio, D.A. Waki, M.L.C.P. Da Silva, Thermal analysis of ground tire rubber devulcanized by microwaves, J. Therm. Anal. Calorim. 87 (2007) 893-897. https://doi.org/10.1007/s10973-0057419-8. 
82. O. Alexandrova, K.E. Kaloush, J.O. Allen, Impact of asphalt rubber friction course overlays on tire wear emissions and air quality models for Phoenix, Arizona, Airshed, Transp. Res. Rec. J. Transp. Res. Board. 2011 (2007) 98-106. https://doi.org/10.3141/2011-11.

83. A. Dehaut, A.-L. Cassone, L. Frère, L. Hermabessiere, C. Himber, E. Rinnert, G. Rivière, C. Lambert, P. Soudant, A. Huvet, G. Duflos, I. Paul-Pont, Microplastics in seafood: benchmark protocol for their extraction and characterization, Environ. Pollut. 215 (2016) 223-233. https://doi.org/10.1016/j.envpol.2016.05.018.

84. A. Käppler, F. Windrich, M.G.J. Löder, M. Malanin, D. Fischer, M. Labrenz, K.-J. Eichhorn, B. Voit, Identification of microplastics by FTIR and Raman microscopy: a novel silicon filter substrate opens the important spectral range below $1300 \mathrm{~cm}-1$ for FTIR transmission measurements, Anal. Bioanal. Chem. 407 (2015) 6791-6801. https://doi.org/10.1007/s00216-015-8850-8.

85. M. Dong, Q. Zhang, X. Xing, W. Chen, Z. She, Z. Luo, Raman spectra and surface changes of microplastics weathered under natural environments, Sci. Total Environ. 739 (2020). https://doi.org/10.1016/j.scitotenv.2020.139990.

86. A. Carmichael, Man-made fibers continue to grow, Text. World. 2015 (2015). https://www.textileworld.com/textile-world/fiber-world/2015/02/man-made-fibers-continue-to-grow/ (accessed August 17, 2020).

87. M.C. Zambrano, J.J. Pawlak, J. Daystar, M. Ankeny, J.J. Cheng, R.A. Venditti, Microfibers generated from the laundering of cotton, rayon and polyester based fabrics and their aquatic biodegradation, Mar. Pollut. Bull. 142 (2019) 394-407. https://doi.org/10.1016/j.marpolbul.2019.02.062.

88. M.A. Browne, P. Crump, S.J. Niven, E. Teuten, A. Tonkin, T. Galloway, R. Thompson, Accumulation of microplastic on shorelines woldwide: Sources and sinks, Environ. Sci. Technol. 45 (2011) 91759179. https://doi.org/10.1021/es201811s.

89. R.E. Engler, The complex interaction between marine debris and toxic chemicals in the ocean, Environ. Sci. Technol. 46 (2012) 12302-12315. https://doi.org/10.1021/es3027105.

90. J. Brandon, M. Goldstein, M.D. Ohman, Long-term aging and degradation of microplastic particles: Comparing in situ oceanic and experimental weathering patterns, Mar. Pollut. Bull. 110 (2016) 299308. https://doi.org/10.1016/j.marpolbul.2016.06.048.

91. Y.K. Song, S.H. Hong, M. Jang, J.-H. Kang, O.Y. Kwon, G.M. Han, W.J. Shim, Large Accumulation of Micro-sized Synthetic Polymer Particles in the Sea Surface Microlayer, Environ. Sci. Technol. 48 (2014) 9014-9021. https://doi.org/10.1021/ES501757S.

\section{Figures}

\section{Figure 1}


$<\mathrm{p}>$ Map showing drag transects A1 to A5 used for sampling of seawater on coast of Fortaleza, Brazil. $</ p><p><b r></ p>$

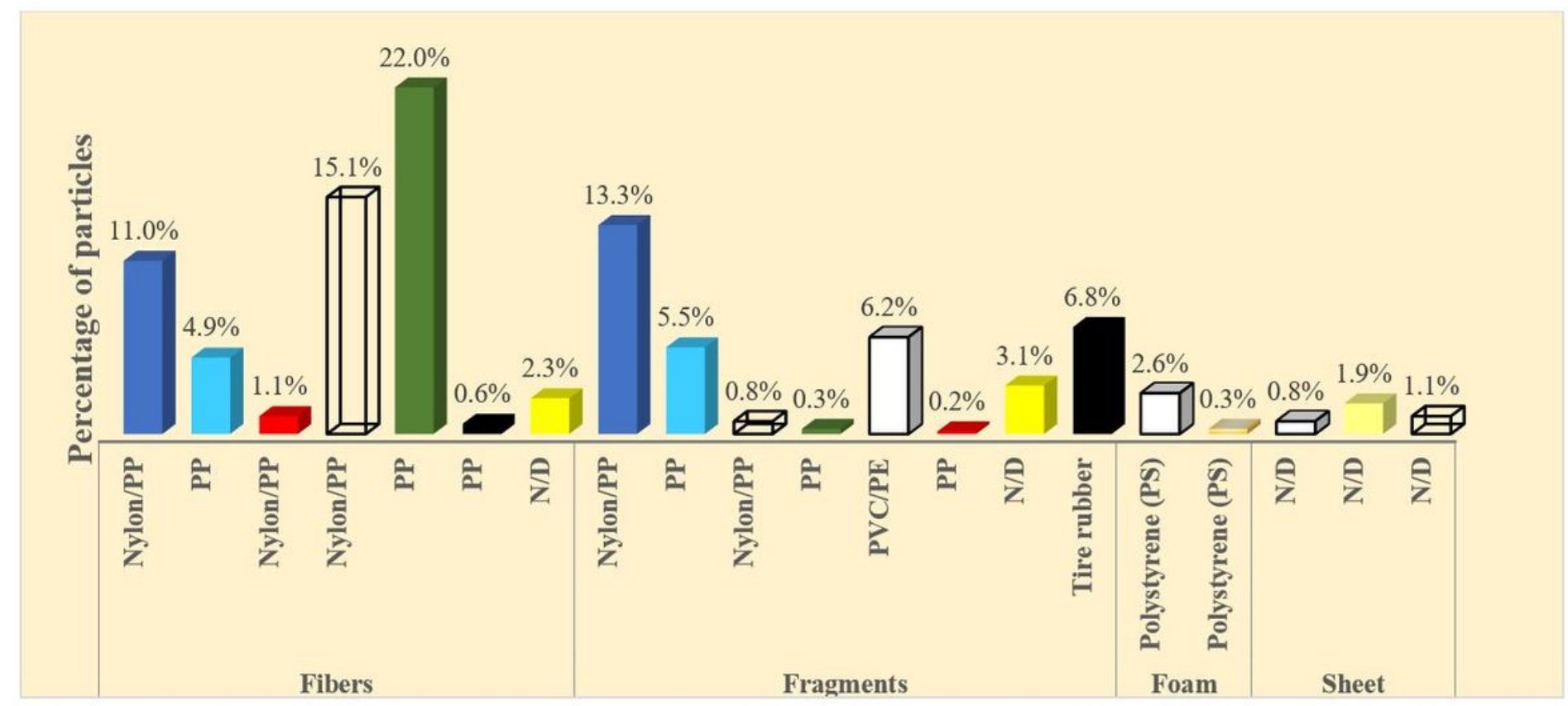

Figure 2

$<p>$ Distribution of microplastics according to particle shape and suspected type polymer based on morphological characterization. Color of bars represents color of particles. $</ p><p><b r></ p>$

Figure 3

$<p>$ Classification of particles according to shape: A) and A1) blue fibers, B) yellow fragment, C) black fragment, D) dark green and blue fragments, E) white fragment, F) yellow sheet, G) foam $</ p><p><b r></ p>$ 


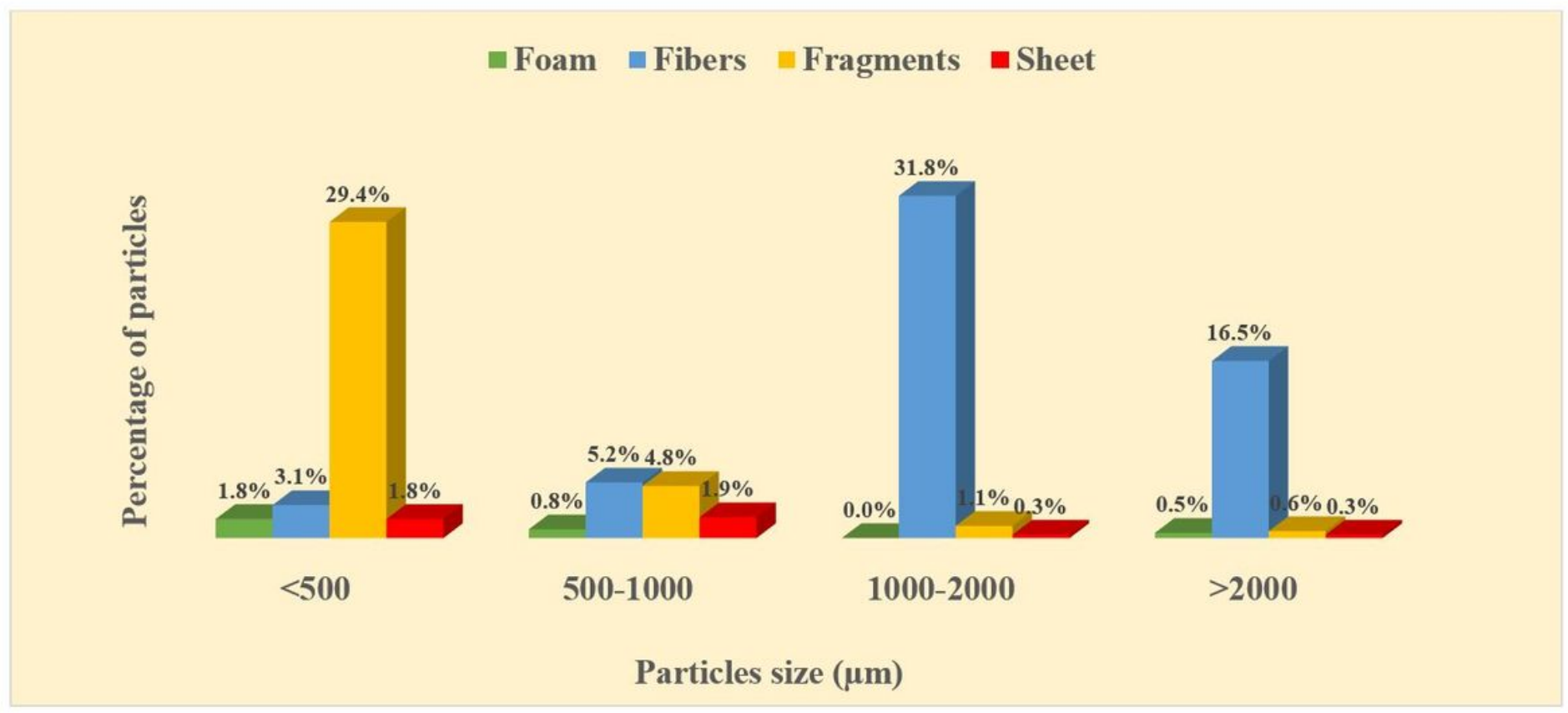

\section{Figure 4}

$<p>$ Distribution of microplastics according to shape and size of particles. $</ p><p><b r></ p>$

\section{Supplementary Files}

This is a list of supplementary files associated with this preprint. Click to download.

- SupplementaryInformationSI.pdf 